\title{
RESEARCH ON EMERGENT SOIL EXPLORATION SYSTEM USING REMOTELY OPERETED ROBOT
}

\author{
Mikio Okano \\ Technical Development Division \\ Fujita Corporation. \\ 2025-1 ono atugi -shi Kanagawa 243-0125 Japan \\ Hiroshi Mayuzumi \\ Technical Headquarters. \\ Kawasaki Geological Engineering Co.Ltd \\ 2-11-15 mita minato-ku Tokyo 108-8337 Japan \\ Katsuyuki Baba \\ Technical Reserch Division \\ TMSUK Co.Ltd \\ 84-9 nishiminatomachi kokurakita-ku kitakyuusyu-shi \\ Fukuoka 803-0801 Japan
}

\author{
Kazuhiro Chayama \\ Civil Engineering Division \\ Fujita Corporation \\ 4-25-2 sendagaya sibuya-ku Tokyo 151-0051 Japan \\ Takuo Muroyama \\ Technical Devision. \\ Kawasaki Geological Engineering Co.Ltd \\ 2-11-15 mita minato-ku Tokyo 108-8337 Japan
Shiro Fujita
Technical Robot Business Marketing Division TMSUK Co.Ltd
1-7-8 kimachi kokurakita-ku kitakyusyu-shi Fukuoka 803-0851 Japan

\begin{abstract}
Following typhoons, floods, earthquakes and volcanic eruptions, it is often necessary to undertake emergency works under the continual threat of secondary disasters. In order to execute these works as safely as possible, it is important to rapidly characterize ground conditions at the disaster sites. In order to achieve this, a portable cone penetration testing apparatus that could be attached to a two-armed, remotely operated robot was developed.

This paper outlines the development of the remotely controlled cone penetration test system and the test results obtained to confirm the applicability of the apparatus to real-world situations.
\end{abstract}

Keywords: Soil exploration, remote control, portable corn penetration test, robot, disaster prevention and restoration

\section{INTRODUCTION}

Recently, there have been many large-scale landslides caused by earthquakes, volcanic activities and typhoons. In order to undertake disaster restoration and prevention works quickly and safely, it is crucial to research and develop rapid methods for characterizing ground conditions.

Following the Mid Niigata Prefecture Earthquake (Japan, 2004), a problem arose in terms of how to secure roads for disaster relief transport following large-scale and widespread landslides occurred in mountainous areas. Aerial laser surveying and photogrammetry were tried along with field explorations by experts at that time. However, due to the continual threat of aftershocks, secondary landslides in unstable slopes and debris flows, it was very difficult to guarantee the safety of experts and workers. To solve these problems, it is very important to research and develop unmanned ground testing apparatus utilizing remotely operated robots to quickly and safely characterize collapsed grounds and suggest suitable countermeasures based on the obtained information.
A series of developments have been carried out for ground surveying methods in hazardous areas utilizing a remotely operated robot with two arms. This paper outlines the development of the remotely controlled portable cone penetration test system and assesses test results obtained to confirm the applicability of the apparatus to real-world situations.

\section{TARGETED GROUND SURVEYING ITEM}

\subsection{Selection of surveying item}

There are many cases where manned surveying works cannot be carried out at disaster sites because of the threat of secondary disasters.

Owing to recent technology developments, it is now possible to survey site situations using remote methods such as aerial laser surveying system and satellite image analysis followed by identifications of hazardous areas, selection of escape routes and initial planning of disaster restoration works.

However, in order to come up with detailed countermeasures for full-scale restoration works with satisfactory safety for workers, it is important to 
characterize ground conditions in detail from the surface to some depth, in order to identify localized areas of weak strength and sliding surfaces.

Figure-1 shows well-known ground investigation methods. In the course of this research and development, the suitability of three methods (the portable cone penetration test, the portable cone dynamic penetration test and the electromagnetic method) were evaluated. From these methods, the portable cone penetration method was selected as the results from this method are the most useful for predicting hazard ratings at the first stage of disaster occurrences, planning of routes for construction vehicles necessary for disaster relief, and qualitatively evaluating trafficability for construction vehicles.

\subsection{Portable cone penetration test}

The portable cone penetration test uses the equipment shown in Photo-1 with a procedure shown in Figure-2. Photo-2 shows the equipment in use.

This test characterizes cone penetration resistances for soft grounds such as cohesive soils and humic soils, and the values are utilized for identification of ground composition, ground strength, trafficability for construction vehicles and bearing capacity of grounds for housing.

In this test, a cone is driven in to the ground at a power of around $1 \mathrm{kN}$. It is difficult to apply this method to sandy grounds because the cone resistance caused by circumference friction is relatively high in this case. In addition, reliable resistance values can only be obtained to depths of between $3 \mathrm{~m}$ and $5 \mathrm{~m}$ because the circumference resistance of the rod increases as the penetration depth increases.

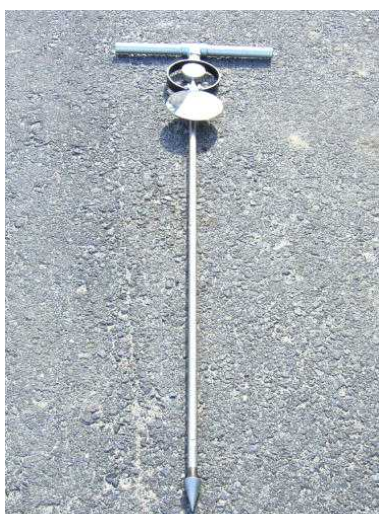

Photo-1 Portable cone penetration testing apparatus

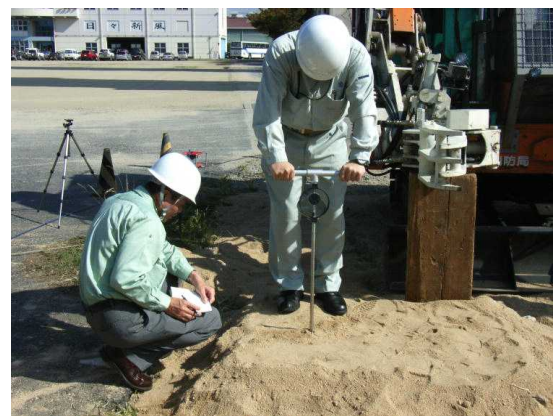

Photo-2 Portable cone penetration test by conventional method

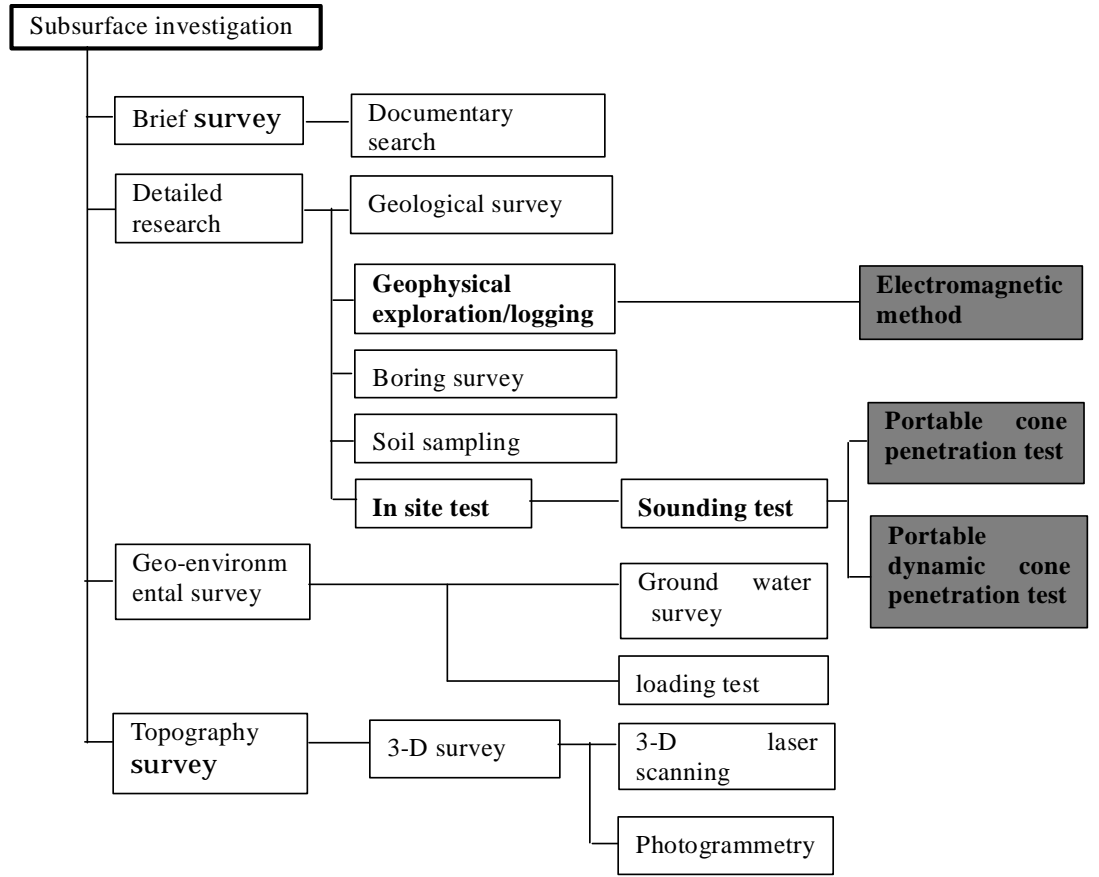

Figure-1 Present ground investigation method 


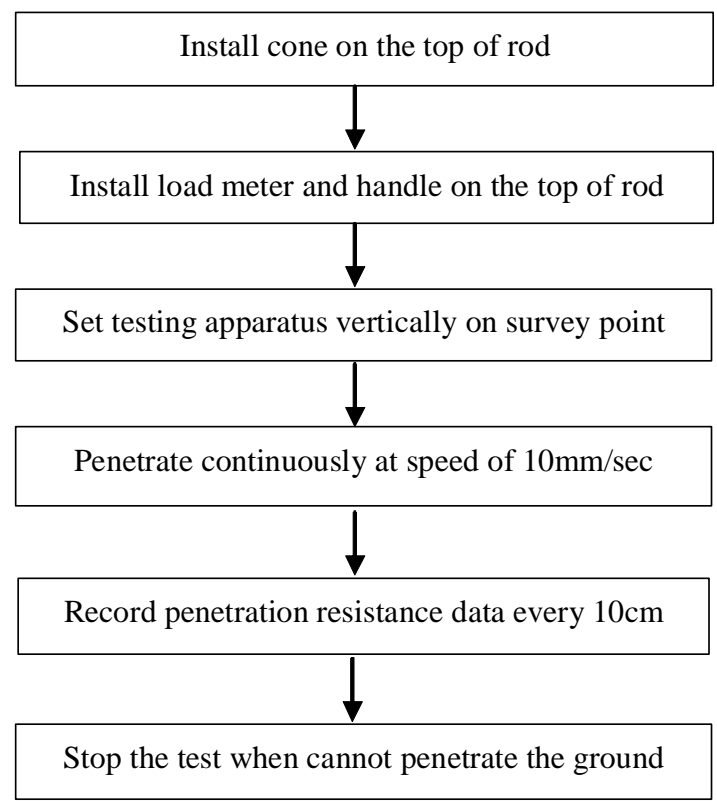

Figure-2 Flow of cone penetration test

\section{THE OUTLINE OF PORTABLE CONE PENETRATION APPARATUS}

\subsection{The base machine}

The remotely controlled robot (with two arms) as shown as Photo-3, to which the cone penetration test apparatus is attached, was remodeled from a commercially available small-sized backhoe with a bucket volume of 0.11 $\mathrm{m}^{3}$.

The robot is $3.45 \mathrm{~m}$ in height, $2.4 \mathrm{~m}$ in width and $3.5 \mathrm{~m}$ in length with a total weight of 5 tons. Each arm has nine movement degrees and a loading capacity of $500 \mathrm{~kg}$.

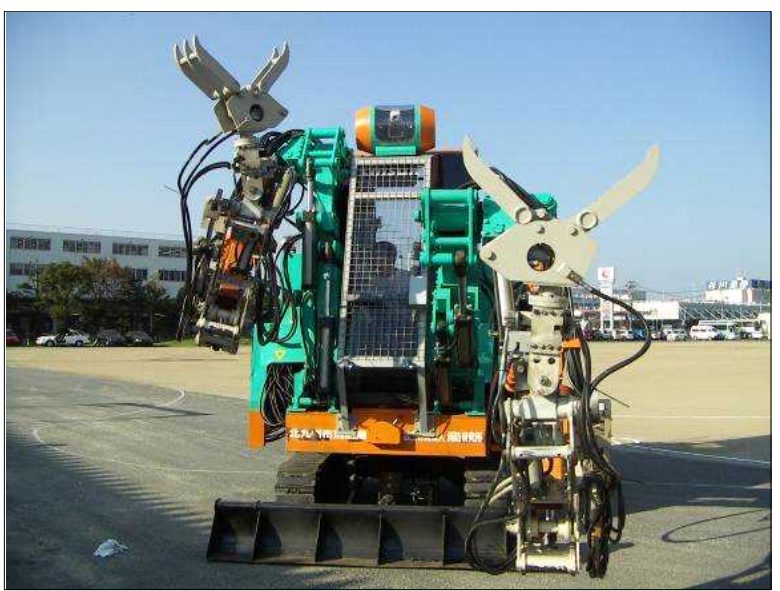

Photo-3 whole view of robot with two arms

\subsection{The outline of the developed apparatus}

The developed cone penetration testing system attached to the robot uses oil pressure sourced from the remotely controlled robot, and the penetration pressure and the penetration depth are measured using a load cell and an encoder.

Figure- 3 shows a schematic of the portable cone penetration apparatus developed. The apparatus consists of an oil pressure cylinder serially connected with a rod (with a cone at the top) which is pushed into the ground, a load cell, slide shafts to prevent misalignment of the rod center, a rolling type encoder and a frame. The oil pressure sourced from the remotely controlled robot is $14 \mathrm{Mpa}$, and the inner diameter of the oil pressure cylinder is $\varphi 32 \mathrm{~mm}$. The penetration velocity is set to a value of $1 \mathrm{~cm} / \mathrm{sec}$ which conforms to the test standard defined by the Japanese Geotechnical Society ${ }^{1)}$ and the penetration force is set at a power of $1 \mathrm{kN}$ which is similar to body weight of an ordinary adult man.
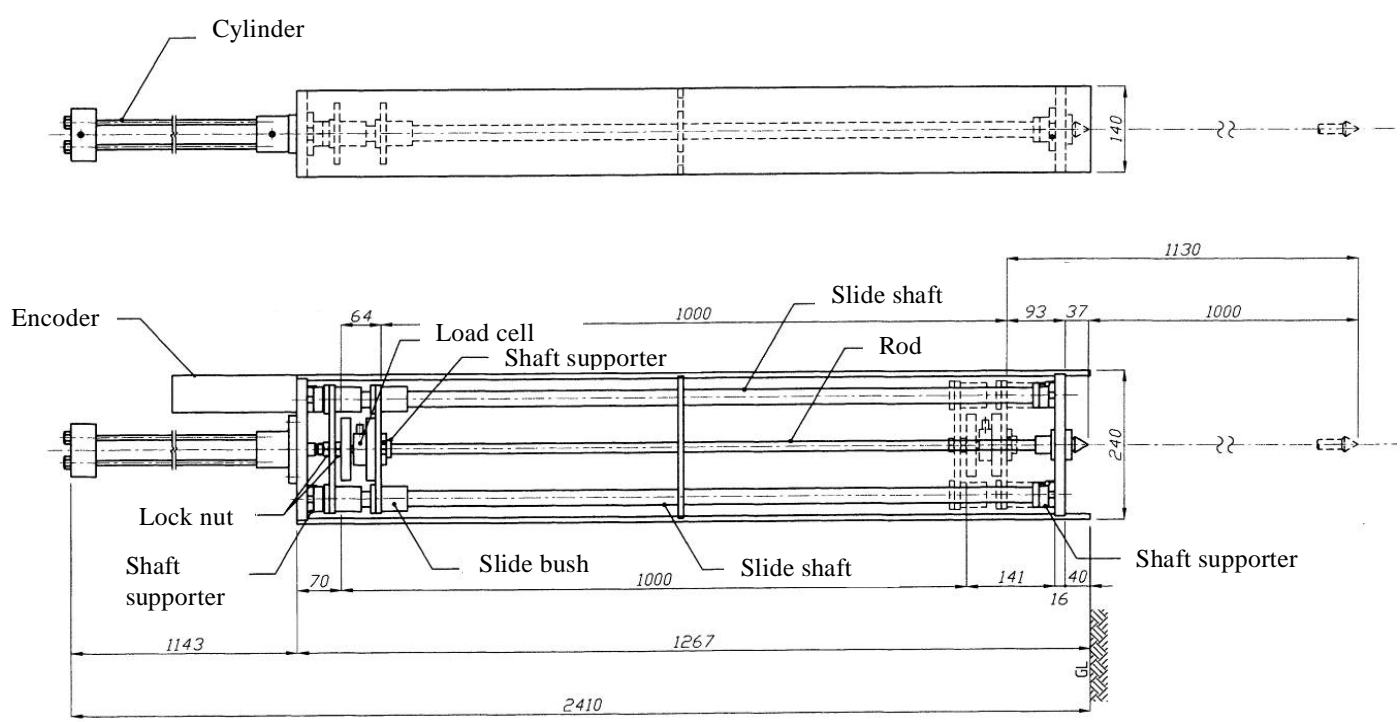

Figure-3 O utline of portable cone penetration apparatus 

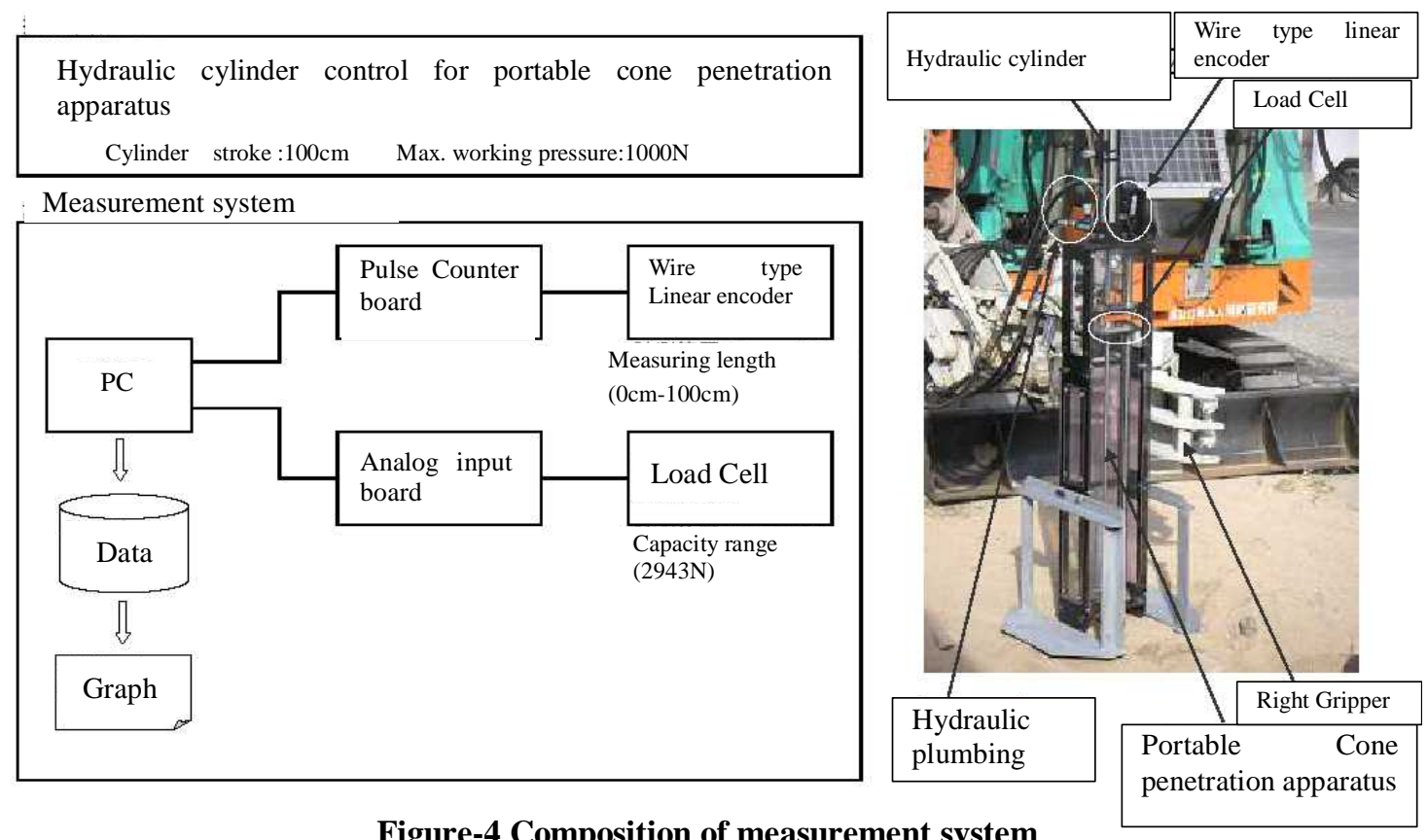

Figure-4 Composition of measurement system

\subsection{The measurement system}

Figure-4 shows a schematic of the measurement system. The portable cone penetration test apparatus was attached to the right arm of the robot, and the apparatus was remotely controlled. The penetration resistances were measured by a load cell, and the penetration length was measures by a wire typed linear encoder. The measured data was forwarded to a computer, and was also able be monitored at the robot operator's seat as shown in Photo-4.

\section{EXAMINATION TESTS}

\subsection{Test items}

A number of tests were undertaken to confirm the effectiveness of this system. The tests aimed to assess 1) the differences between expected and real world performance, 2) the reproducibility of the test results and 3) the difference between the test results by unmanned and manned tests carried out at the same time. Photo-5 shows the situations for tests using remotely controlled system.

The tests were carried out in an excavation pit filled with decomposed granite to a depth of $1 \mathrm{~m}$ in three different ways; 1)tipped into the pit(CASE-1),2) compacted by tampers (CASE-2) and 3)further compacted with watering (CASE-3).

\subsection{Test results}

The examination situations are shown in Photo-5. The examination test results are shown in Figure-5, and it can be seen the results from the remotely controlled system is similar to the results from the conventional manned system. Moreover, it can be seen that the penetration velocity of the remotely controlled system has almost same values, and the reproducibility is confirmed.
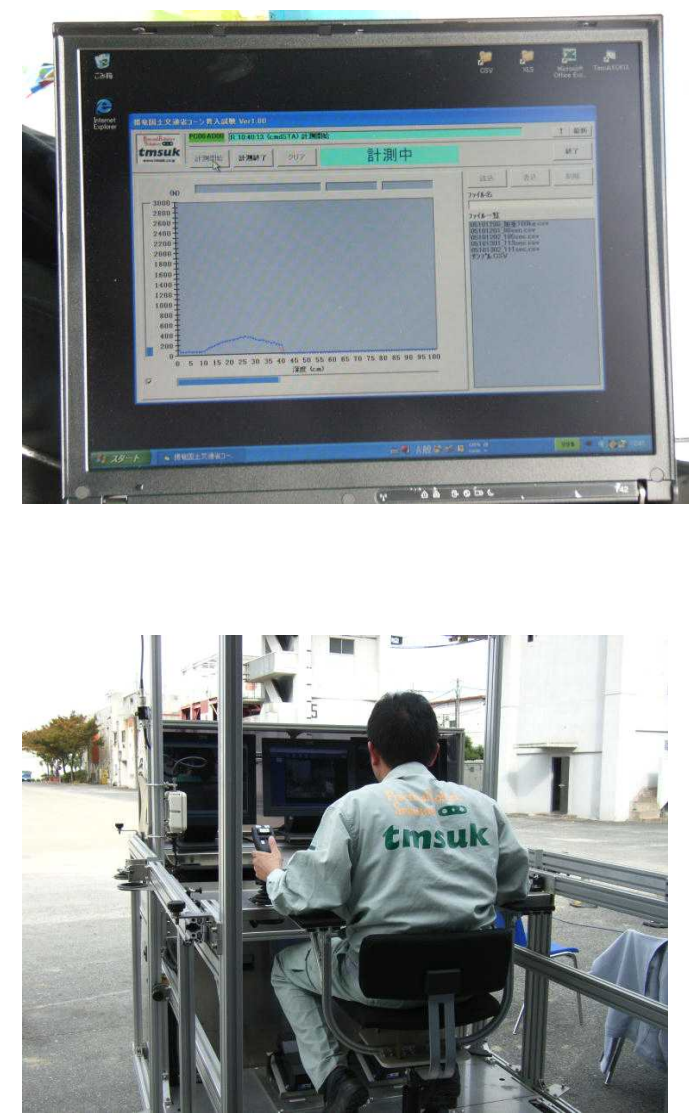

Photo-4 The remote operation situation 
However, the penetration velocities of manned system were fluctuated because the loading in the manned system was made by a man's weight and the actual loading forces were slightly different in each test.

In the tests by the remotely controlled system, the resistance values were measured at the interval of $1 \mathrm{~cm}$. It was found that such 'continuous' data can reasonably characterize heterogeneous ground conditions, weak thin ground layers (such as sliding surfaces) and ground strengths near ground surfaces (which can effectively be used to estimate trafficability for construction vehicles).
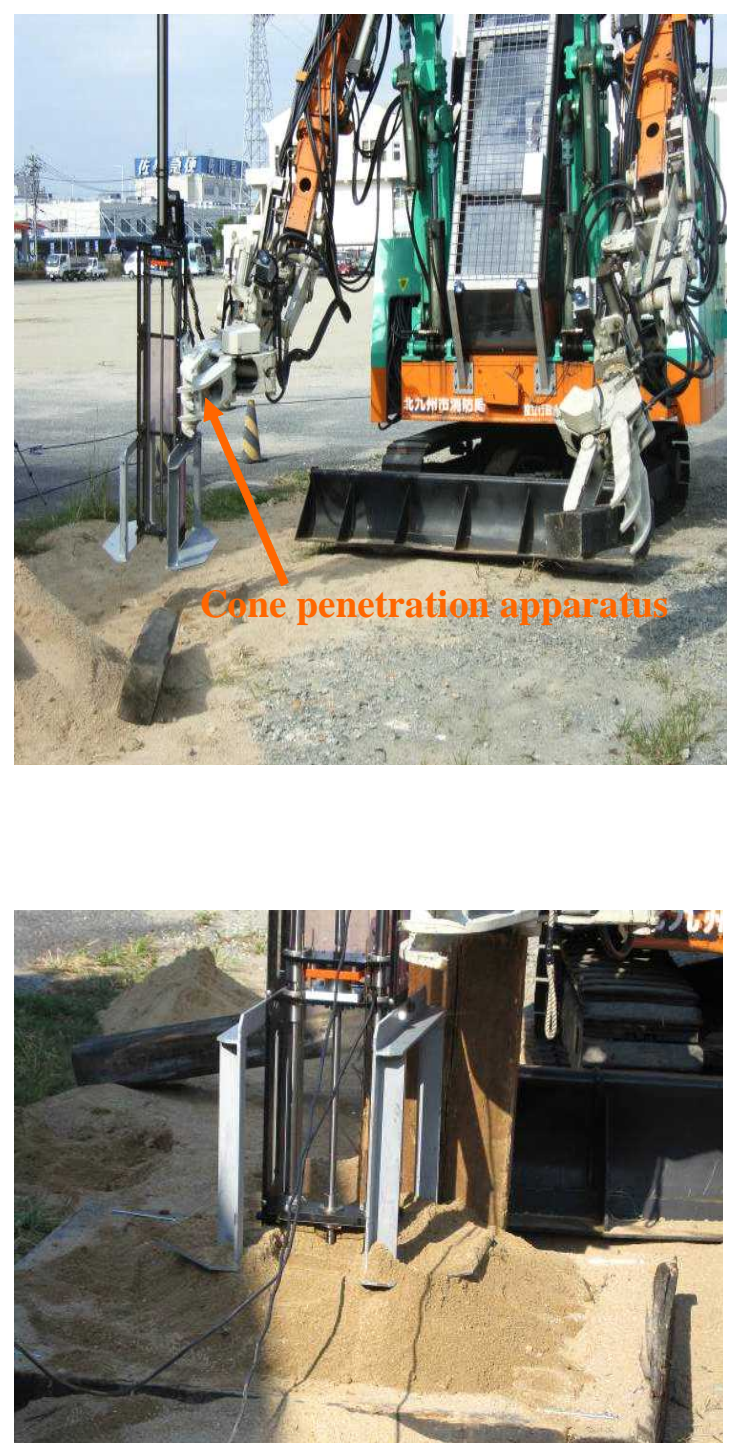

Photo-5 Cone penetration test by remotely controlled method
Cone penetration resistance $\mathrm{q}_{\mathrm{c}}\left(\mathrm{kN} / \mathrm{m}^{2}\right)$

$\begin{array}{lllllllll}0 & 200 & 400 & 600 & 800 & 1000 & 1200 & 1400 & 1600\end{array}$

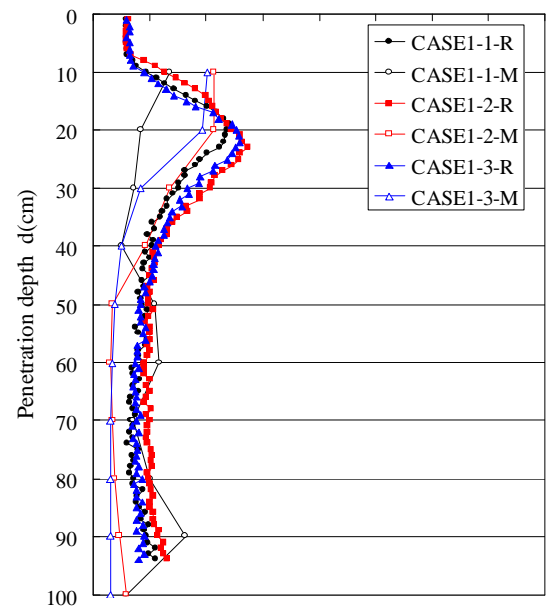

CASE-1

Cone penetration resistance $\mathrm{q}_{\mathrm{c}}\left(\mathrm{kN} / \mathrm{m}^{2}\right)$ $\begin{array}{llllllll}200 & 400 & 600 & 800 & 1000 & 1200 & 1400 & 1600\end{array}$

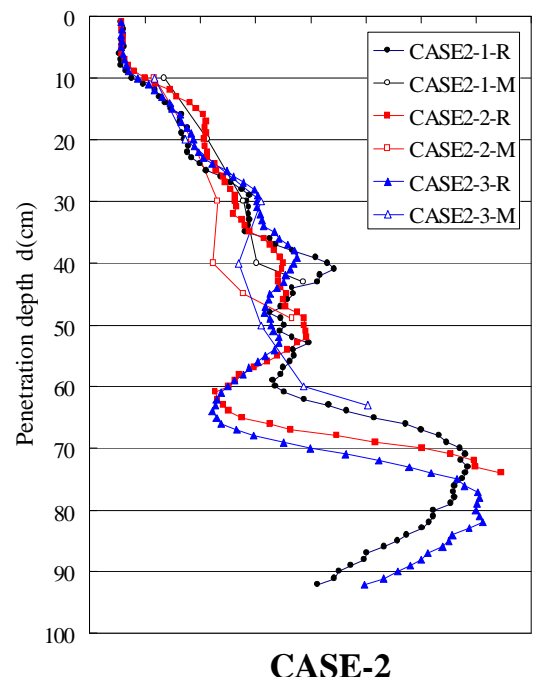

Cone pnetration resistance $\mathrm{q}_{\mathrm{c}}\left(\mathrm{kN} / \mathrm{m}^{2}\right.$ $\begin{array}{llllllll}200 & 400 & 600 & 800 & 1000 & 1200 & 1400 & 1600\end{array}$

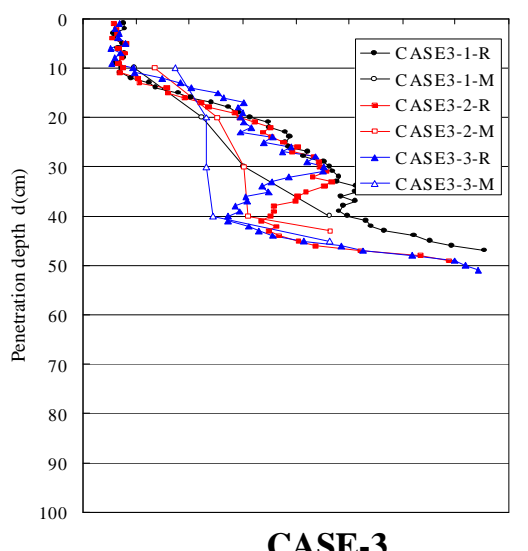

Figure-5 M easurement result

$R$ : remotely controlled method $M$ : manned method 


\section{ISSUESTO BE SOLVED}

One of the issues to be solved is that the remotely controlled system developed can not currently characterize ground at depth as extension rods cannot be added. In addition to the improvements of the cone penetration test apparatus, we intend to develop remotely controlled systems including portable dynamic cone penetration test and electromagnetic method which can explore hard ground (such as rock) and characterize ground conditions at greater depths (to explore large-scale land slides) and can be attached easily to the robot. Furthermore we intend to develop an integrated emergent soil exploration system by incorporating GPS system and IT technologies into the test systems.

\section{ACK NOWLEDGMENT}

This research was funded and supported by the Advanced Construction Technology Center in fiscal year 2004. We express our hearty thanks to the related persons.

\section{REFERENCES}

[1]The Japan Geotechnical Society, "Ground exploration methods and interpretations", June, 2004. 